\title{
ANÁLISE DE IMPLANTAÇÃO DE UM SISTEMA DE APROVEITAMENTO DE ÁGUA PLUVIAL EM UM EMPREENDIMENTO RESIDENCIAL NA CIDADE DE RECIFE-PE
}

\author{
Micaella Raíssa Falcão de Moural, Simone Rosa da Silva², Emília Xavier do Rêgo Barros ${ }^{3}$ \\ IDepartamento de Eng. Civil e ambiental, Universidade Federal de Pernambuco (UFPE), Recife, Pernambuco-Brasil. \\ 2 Departamento de Eng. Civil, Escola Politécnica de Pernambuco (POLI-UPE), Recife, Pernambuco-Brasil. \\ 3Escola Politécnica de Pernambuco (POLI-UPE), Recife, Pernambuco-Brasil.
}

*E-mail: micaellaraissa@hotmail.com

\section{RESUMO}

Os sistemas de aproveitamento de água pluvial (SAAP) para fins não potáveis em edificações representam uma das medidas para reduzir a demanda de água potável e minimizar os problemas relacionados à disponibilidade dos recursos hídricos. $\mathrm{O}$ trabalho avaliou a viabilidade técnica e financeira da implantação de um SAAP em um empreendimento residencial- em construção- na Região Metropolitana do Recife por meio de uma simulação, fazendo uso da água da chuva para fins não potáveis na rega de jardins. Para tal, realizou-se um estudo dos índices pluviométricos da região e sua periodicidade, avaliando-se os meses de maior e menor precipitação. O reservatório de armazenamento foi dimensionado por meio do método computacional Netuno e em diferentes cenários de área de captação, de maneira a avaliar a situação ideal para suprir a demanda mensal de água da rega dos jardins. A análise econômica da construção do sistema mostrou que a sua implantação em uma edificação residencial com características similares a utilizada no estudo é tecnicamente e economicamente viável.

Palavras-chave: SAAP. Reservatório. Netuno.

\section{Introdução}

Sabe-se que a água é fundamental para suprir as necessidades dos seres vivos, além de um importante fator de produção para diversas atividades, sendo essencial para o desenvolvimento econômico e tecnológico em todo o mundo [1]

No atual cenário mundial, entretanto, as mudanças climáticas, a urbanização, a ausência de uma gestão hídrica adequada e o uso inconsequente da água são alguns dos fatores responsáveis pela grave crise hídrica que afeta várias regiões. Deste modo, tornam-se cada vez mais urgentes alternativas que visem à conservação e redução de desperdícios deste recurso, tendo em vista a carência de disponibilidades hídricas e a dificuldade de se encontrar novas reservas.

As relações mantidas pelos atores sociais com os recursos hídricos e seu modo de apropriação, no Brasil, conduziram o país ao atual estado de degradação ambiental e escassez [2]. Segundo os autores, há uma contínua necessidade de se estabelecer um controle social efetivo sobre a água e a biodiversidade e é, neste sentido, que alguns instrumentos de caráter normativo podem ser apresentados para a consolidação deste processo.

A ABNT (Associação Brasileira de Normas Técnicas) desenvolveu no ano de 2007 a norma brasileira NBR 15.527/2007, que aborda o aproveitamento das águas de chuva através de coberturas em áreas urbanas para fins Não Potáveis, como irrigação de áreas permeáveis (jardins) e plantas ornamentais; descargas de bacias sanitárias; limpeza de calçadas, ruas e pátios; lavagem de veículos, espelhos d'água e usos industriais.

Os sistemas de aproveitamento de água pluvial representam uma das medidas contemporâneas de maior destaque no que se refere à sustentabilidade hídrica em áreas urbanas. Tais sistemas possibilitam a redução do consumo de água potável, a minimização de enchentes/alagamentos e surgem como 
alternativas de abastecimento em meio a um cenário crítico de indisponibilidade hídrica.

$\mathrm{Na}$ análise para a implantação de um SAAP, deve-se levar em consideração o alcance do projeto, a população que utilizará as águas de chuva, a determinação da demanda a ser definida pelo projetista do sistema, os estudos das séries históricas e a média das precipitações da região onde será implantado o sistema de captação [3].

Há exemplos de diversos relatos de aproveitamento de água de chuva na história [4]. No Brasil, até a década de 80 existiam poucas experiências de aproveitamento de água pluvial [1]. O autor reforça que tal aproveitamento passou a ganhar força no país através de experiências com cisternas para água da chuva e barragens subterrâneas no semiárido.

Atualmente, no que se refere aos aspectos legislativos, a NBR 15.527/2007 [5] recomenda seis métodos de cálculos para dimensionamento dos reservatórios de SAAP's, são eles: Método de Rippl; Método da Simulação; Método Azevedo Neto; Método Prático Alemão; Método Prático Inglês e Método Prático Australiano.

Este artigo consistiu em avaliar a viabilidade técnica e financeira da implantação de um sistema de aproveitamento de água pluvial em um empreendimento residencial da Região Metropolitana do Recife por meio de uma simulação, fazendo uso da água pluvial para fins não potáveis na rega de jardins.

\section{Metodologia}

O procedimento metodológico escolhido foi o estudo da simulação de construção de um reservatório para armazenamento de água pluvial em um empreendimento que possui projeto de rede de coleta de água da chuva. Além de estudar os parâmetros técnicos para execução de um SAAP em um empreendimento deste porte, foi realizada uma análise da viabilidade econômica para construtora e o comprador em implantar, de fato, este sistema.

\subsection{Caracterização do objeto de estudo e levantamento de dados}

A primeira etapa do trabalho consistiu na caracterização do empreendimento, com avaliação das plantas de cobertas, áreas construídas, instalações hidráulicas/hidrossanitárias e respectivos custos, entre outros. Em seguida, foram levantados diversos tipos de dados, como por exemplo: estimativa do número de moradores do empreendimento; previsão da demanda de água a ser abastecida pela água da chuva; determinação das áreas de captação; dados pluviométricos da região; custos de materiais e mão de obra.

Após coletados os dados, foi realizada a identificação do posto pluviométrico (e levantamento da série histórica pluviométrica), a definição da área de coleta, determinação do coeficiente de escoamento superficial e a determinação das demandas hídricas. Para determinação das demandas, fez-se a estimativa por meio de parâmetros da demanda residencial de água potável para uso externo, conforme [4], que adota o valor de $2 \mathrm{~L}$ $\mathrm{dia}^{-1} / \mathrm{m}^{2}$ para uso externo em jardim.

\subsection{Projeção do reservatório de armazenamento}

Para o cálculo do volume do reservatório de armazenamento de águas pluviais foi utilizado o programa computacional Netuno, além de estudados cinco métodos recomendados pela NBR15.527/2007 [5]: o Método de Rippl, Método da Simulação, Método prático alemão, Método prático inglês e Método Azevedo Neto.

O Netuno é um programa computacional desenvolvido pelo LabEEE (Laboratório de Eficiência Energética em Edificações) da Universidade Federal de Santa Catarina, que tem como objetivo determinar o potencial de economia de água potável em função da capacidade do reservatório, através da simulação do aproveitamento de água pluvial para usos não potáveis.

Apresentam-se como dados de entrada do programa: área de captação, série histórica da precipitação pluviométrica diária, descarte inicial de chuva, consumo diário per capita de água potável, número de moradores, coeficiente de escoamento superficial e percentual da demanda total a ser substituída por água pluvial. Foram utilizados os dados de precipitações diárias da cidade de Recife de 01/03/1961 a 31/12/2014, fornecidos pelo INMET.

\subsection{Análise econômica}

Adotaram-se como custos de implantação do sistema os materiais necessários para execução dos condutores de água pluvial e custos com mão de obra para execução das instalações e construção do reservatório. A simulação de custos foi realizada com base em cotações feitas por fábricas e distribuidoras para construtoras de grande porte na cidade do Recife para compra dos materiais em maio/2015.

Os custos com mão de obra foram obtidos através de estimativa dos dias trabalhados necessários para executar $\mathrm{o}$ projeto, considerando a remuneração mensal da tabela salarial (Recife Base Marreta) e produtividade estipulada pela construtora do empreendimento. O tempo de retorno do investimento foi verificado pelo método do payback simples que, pode ser considerado em um pré-estudo para aceitação ou rejeição de determinado projeto [6]. 


\section{Resultados}

\subsection{Caracterização do empreendimento e estimativas das} demandas

O empreendimento está localizado no bairro da Jaqueira, cidade de Recife, Pernambuco, e está instalado em um terreno de $7.000 \mathrm{~m}^{2}$ que preserva árvores centenárias, como mangueiras, jambeiros e caneleiros. Composto por 03 torres com 15 andares cada, 02 apartamentos por andar, sendo 04 suítes em cada apartamento, com sala para 03 ambientes e 03 vagas na garagem, com total de 270 vagas no Edifício Garagem.

O condomínio ainda possui área de lazer completa, piscina adulta e infantil, espelho d'água, deck Molhado, salões de Festa (um em cada torre), salão de jogos, espaço fitness, bicicletário, 02 playgrounds, espaço Gourmet e praças de convívio ao ar livre. A obra teve início em 01 de novembro de 2013 e previsão de término para 30 de junho de 2016. A figura 1 mostra a planta do detalhamento das cobertas do empreendimento.

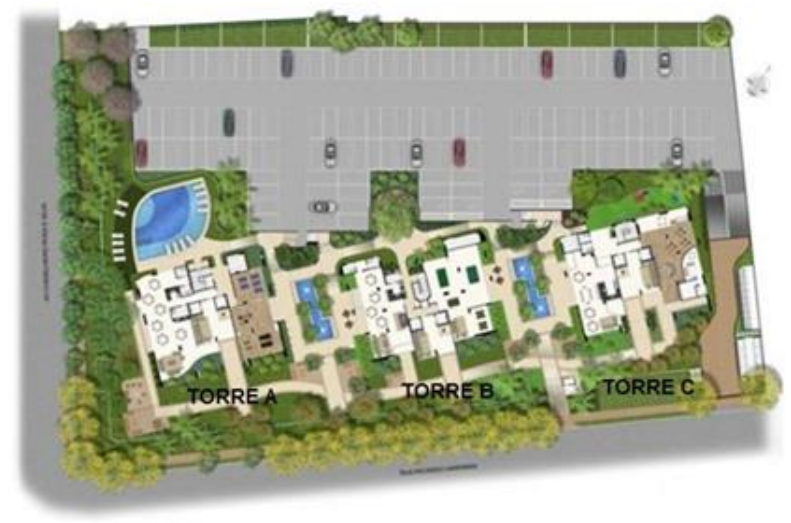

Figura 1- Cobertas do empreendimento

Por se tratar de um empreendimento residencial composto por 04 quartos sociais com suíte e 01 de serviço por apartamento, sendo considerada uma residência de padrão alto pela construtora, estipulou-se 6 moradores por apartamento. Tal estimativa se justifica pelo perfil do empreendimento, o bairro e o custo de compra do apartamento. Não foi utilizada a estimativa de Creder [7], de que em cada quarto social é ocupado por duas pessoas e cada quarto de serviço por uma pessoa. Deste modo, a estimativa chegou a um total de 540 pessoas em todo o empreendimento.

Foi estimada uma demanda fixa de água diária da população do prédio de 200 litros per capita [7]. Logo, para efeitos de dimensionamento, a demanda de água da população por torre será equivalente a $36 \mathrm{~m}^{3} \mathrm{dia}^{-1}$. Sendo o total do consumo diário do empreendimento de $108 \mathrm{~m}^{3}$.

A demanda de água a ser suprida com a captação de água da chuva será a necessária para rega dos jardins do empreendimento. A área de jardim no empreendimento é de 2.279,25 m², deste modo, são necessários, 4558,5 $\mathrm{L} \mathrm{dia}^{-1}$, ou 4,56 $\mathrm{m}^{3} \mathrm{dia}^{-1}$, para suprir a demanda de rega conforme Tomaz [4].

Considerou-se para o dimensionamento do reservatório de acumulação, o caso extremo, de rega de área verde durante 30 dias do mês, sendo a demanda mensal de $136,76 \mathrm{~m}^{3}$ de água a ser substituída por água da chuva.

$\mathrm{Na}$ hipótese das cobertas com áreas de captação individuais, a demanda mensal calculada foi de $45,56 \mathrm{~m}^{3}$ por torre, sendo necessários $1519,5 \mathrm{~L} \mathrm{dia}^{-1}$. Nesta hipótese as torres são consideradas individualmente, tendo cada torre uma área de captação de água da chuva, uma área de jardim e uma demanda fixa de água a ser substituída.

\subsection{Dados Pluviométricos e Áreas de Captação}

Para o programa computacional Netuno, utilizou a série histórica diária de precipitação de 01/03/1961 a 31/12/2014, visto que o programa exige a entrada da precipitação diária do período mais longo possível. A precipitação média mensal obtida para o período avaliado foi $197,96 \mathrm{~mm}^{\mathrm{mês}}{ }^{-1} \mathrm{e}$ a precipitação média anual foi de $2375,53 \mathrm{~mm}^{\mathrm{ano}}{ }^{-1}$.

No que se refere às áreas de captação de água da chuva do empreendimento, foram consideradas as áreas de coberta (ático) das três torres e o último pavimento do edifício garagem. Todas as superfícies são planas horizontais, sendo o cálculo da área de contribuição realizado através da NBR 10.844/89 [8]. Simularam-se seis diferentes cenários de captação para o dimensionamento do reservatório conforme apresentado na tabela 1.

Tabela 1. Hipóteses das áreas de coleta.

\begin{tabular}{lc}
\hline \multicolumn{1}{c}{ Hipóteses Área de Coleta } & Área captação \\
\hline Hipótese 1- Cobertas individuais & \\
1.1 Torre A & $317,61 \mathrm{~m}^{2}$ \\
1.2 Torre B & $314,5 \mathrm{~m}^{2}$ \\
1.3 Torre C & $326,7 \mathrm{~m}^{2}$ \\
Hipótese 2- Cobertas Juntas & $958,81 \mathrm{~m}^{2}$ \\
Hipótese 3- Edifício Garagem & $2266,67 \mathrm{~m}^{2}$ \\
Hipótese 4- Edf Garagem + 3 cobertas & $3225,48 \mathrm{~m}^{2}$ \\
\hline
\end{tabular}

\subsection{Capacidade do Reservatório de Água Pluvial}

A capacidade do reservatório de água de chuva foi calculada utilizando o programa computacional Netuno. O coeficiente de escoamento adotado foi de $0,80 \quad(80 \%$ de 
aproveitamento). O descarte de escoamento inicial adotado foi 2 $\mathrm{mm}$, conforme NBR 15.527/2007 sugere na falta de dados.

As áreas de captação analisadas foram: as das cobertas separadamente, as áreas das cobertas juntas, o último pavimento do edifício garagem e o conjunto de cobertas e edifício garagem. O consumo diário per capita de água potável estimado foi de 200 $\mathrm{L} \mathrm{dia}^{-1} /$ pessoa, conforme parâmetro adotado por Creder [7]. E a população total estimada de 540 pessoas. A figura 2 permite uma melhor visualização dos dados de entrada utilizados no programa Netuno.

\begin{tabular}{|c|c|c|c|c|}
\hline \multicolumn{3}{|c|}{ Dados de Entrada } & & \\
\hline \multirow{2}{*}{\multicolumn{2}{|c|}{$\begin{array}{l}\text { Consumo diário per capita de água potável } \\
\text { (litros/dia/pessoa) }\end{array}$}} & \multirow{2}{*}{200} & Número de Moradores Total & 540 \\
\hline & & & Número de Moradores por Torre & 180 \\
\hline \multirow{2}{*}{\multicolumn{2}{|c|}{$\begin{array}{l}\text { Consumo diário total de água para jardim } \\
\text { (litros/dia) }\end{array}$}} & \multirow[b]{2}{*}{4558,5} & Coeficiente escoamento superficial & 0,8 \\
\hline & & & Períado de precipitacão pluviométrica diária & $1961 \mathrm{a}$ \\
\hline \multicolumn{2}{|c|}{$\begin{array}{l}\text { Consumo diário por torre de água para jardim } \\
\text { (litros/dia) }\end{array}$} & 1519,5 & $\begin{array}{l}\text { Usos finais de água com fins não potáveis } \\
\text { total (\%) }\end{array}$ & 4,22 \\
\hline \multirow{6}{*}{ Área de captação $\left(\mathrm{m}^{2}\right)$} & Hipótese 1.1 & 317,61 & \multirow{2}{*}{$\begin{array}{l}\text { Usos finais de água com fins não potáveis por } \\
\text { torre (\%) }\end{array}$} & \multirow[t]{2}{*}{12,66} \\
\hline & Hipótese 1.2 & 314,5 & & \\
\hline & Hipótese 1.3 & 326,7 & & \\
\hline & Hipótese 2 & 958,81 & & \\
\hline & Hipótese 3 & 2266,67 & & \\
\hline & Hipótese 4 & 3225,48 & & \\
\hline
\end{tabular}

Figura 2. Dados de entrada programa computacional Netuno.

A simulação foi realizada para reservatórios com diversos volumes, admitindo um volume máximo em litros maior que a demanda diária de água pluvial para que supra o consumo diário e que possa manter uma reserva para épocas de pouca chuva.

A demanda diária de água pluvial é $4558,5 \mathrm{~L} \mathrm{dia}^{-1}$. As simulações foram iniciadas com volume máximo de 120000 litros para todas as hipóteses, pela disponibilidade de área em torno de $60 \mathrm{~m}^{2}$ no terreno para implantação de um reservatório de profundidade de $2 \mathrm{~m}$.

Foi realizada variação de volume em intervalos de 1000 litros, e para cada variação realizada, verificou-se um novo potencial de economia de água potável até atingir o volume do reservatório que promoveu um incremento igual ou inferior $0,5 \%$ de economia de água potável sobre o volume anterior testado [1].

Tais parâmetros foram utilizados para todas as hipóteses de área de captação, variando apenas a percentagem da demanda total a ser substituída por água pluvial, que no caso das cobertas captando individualmente é de $4,22 \%$ visto que cada torre necessita de $1519,5 \mathrm{~L} \mathrm{dia}^{-1}$ para rega dos jardins e o número de moradores de 180 pessoas.

Nas demais hipóteses com área de captação maior que $900 \mathrm{~m}^{2}$, a demanda de rega do jardim a ser substituída por água da chuva é também de 4,22\%, sendo o consumo de água do jardim do empreendimento total de $4558,5 \mathrm{~L} \mathrm{dia}^{-1}$ e o número de moradores 540 pessoas.

Logo, o potencial de economia de água potável será estimado em relação ao consumo total dos moradores. Em resumo, os resultados do dimensionamento do volume ideal do reservatório inferior de acumulação, potencial de economia de água potável e demanda diária de água pluvial, para as diferentes áreas de captação de água da chuva, estão apresentados na Tabela 2.

Tabela 2. Resultados do dimensionamento pelo programa computacional Netuno

\begin{tabular}{lccccc}
\hline & $\begin{array}{c}\text { Área de } \\
\text { captação }\left(\mathbf{m}^{2}\right)\end{array}$ & $\begin{array}{c}\text { Demanda diária água } \\
\text { pluvial }(\mathbf{L})\end{array}$ & $\begin{array}{c}\text { Volume } \\
\text { reservatório }(\mathbf{L})\end{array}$ & $\begin{array}{c}\text { Demanda de água } \\
\text { pluvial atendida } \\
(\boldsymbol{\%})\end{array}$ & $\begin{array}{c}\text { Potencial de economia de } \\
\text { água potável } \\
(\%)\end{array}$ \\
\hline Hipótese 1.1 & 317,61 & 1519,5 & 17000 & 62,74 & 2,83 \\
Hipótese 1.2 & 314,5 & 1519,5 & 17000 & 62,26 & 2,82 \\
Hipótese 1.3 & 326,7 & 1519,5 & 17000 & 63,31 & 2,86 \\
Hipótese 2 & 958,81 & 4558,5 & 23000 & 53,69 & 2,52 \\
Hipótese 3 & 2266,67 & 4558,5 & 30000 & 74,77 & 3,27 \\
Hipótese 4 & 3225,48 & 4558,5 & 33000 & 81,06 & 3,48 \\
\hline
\end{tabular}

\subsection{Análise Econômica}

Para estudar a viabilidade econômica foi realizada a estimativa dos custos das instalações prediais de captação de água de chuva - condutores verticais, horizontais e desvios enterrados - da mão de obra para execução destas instalações e estimou-se o custo do reservatório de acumulação de água pluvial.

O volume ideal selecionado para análise econômica foi o reservatório dimensionado para a hipótese de maior potencial de 
economia de água potável, com captação em todas as coberturas do empreendimento, sendo este o que mais supria a demanda imposta e economiza água potável.

O custo das tubulações, conexões e mão de obra, necessários para execução das instalações prediais de água pluvial foram baseados em preços de compra e de pagamento da construtora. Os condutores orçados são de PVC série normal e PVC série reforçada, com suas devidas conexões.

As caixas de inspeção são de concreto, conforme projeto da construtora. A tabela 3 apresenta um resumo do custo dos materiais para execução das instalações de águas pluviais do empreendimento.

Tabela 3. Custo dos materiais necessários para execução das instalações de águas pluviais no empreendimento

\begin{tabular}{ccc}
\hline Torre A & $\mathrm{R} \$$ & $10.381,64$ \\
Torre B & $\mathrm{R} \$$ & $10.566,90$ \\
Torre C & $\mathrm{R} \$$ & $10.917,92$ \\
Edifício Garagem & $\mathrm{R} \$$ & $15.447,36$ \\
Custo Total & $\mathrm{R} \$$ & $47.313,82$ \\
\hline
\end{tabular}

Os custos com mão de obra foram obtidos através de uma estimativa de tempo de produção dos serviços e custo da execução por mês trabalhado do profissional.

Conforme tabela salarial, o mínimo que o profissional pode receber no mês é R $\$ 1.203,40$, sendo sua hora $\mathrm{R} \$ 5,47$. Enquanto que o servente, na carteira recebe $\mathrm{R} \$ 906,40$, com sua hora normal custando $\mathrm{R} \$ 4,12.0$ tempo de execução de cada serviço foi calculado por histórico de execução do mesmo serviço em obras anteriores da empresa. A Tabela 4 expõe os custos totais adotados para a mão de obra executar cada serviço

Tabela 4. Custos da mão de obra para execução das instalações de águas pluviais

\begin{tabular}{|c|c|c|c|}
\hline & Encanador (R\$) & Servente $(\mathbf{R} \$)$ & Total (R\$) \\
\hline $\begin{array}{l}\text { Coluna de } \\
\text { água pluvial }\end{array}$ & $15.300,00$ & $4.249,20$ & $19.549,20$ \\
\hline $\begin{array}{l}\text { Área comum } \\
\text { (exterior }+ \\
\text { térreo torres+ } \\
\text { destino final) }\end{array}$ & $6.600,00$ & $3.379,20$ & $9.979,20$ \\
\hline $\begin{array}{l}\text { Edifício } \\
\text { garagem }\end{array}$ & $4.400,00$ & $2.252,80$ & $6.652,80$ \\
\hline Ático & $3.300,00$ & $1.689,60$ & $4.989,60$ \\
\hline \multicolumn{3}{|c|}{$\begin{array}{l}\text { Custo total da mão de obra para conclusão das } \\
\text { instalações de água pluvial }\end{array}$} & $41.170,80$ \\
\hline
\end{tabular}

Desta forma, fazendo uma breve análise do orçamento inicial da obra para todas as instalações hidrossanitárias, cerca de $5,5 \%$ do orçamento é destinado à execução dos desvios e destinação de água pluvial. O volume do reservatório escolhido para estimar a implantação do sistema foi o de $33000 \mathrm{~L}$.

Por facilidade de instalação e possibilidade de enterramento, orçou-se o custo de cisterna para armazenamento da água da chuva. Devido à grande área do empreendimento, e à captação estimada ser de quatro cobertas, escolheu-se a opção de instalar vários reservatórios em linha - vasos comunicantes.

Portanto, a simulação é o uso de três cisternas de 10000 litros e uma cisterna de 5000 litros. O preço obtido foi por meio de distribuidora de materiais de construção da cidade, com frete incluso.

A Tabela 5 mostra os custos totais das cisternas, representando apenas $2,63 \%$ do orçamento inicial para as instalações hidrossanitárias, e $0,08 \%$ do orçamento de toda a obra.

Tabela 5. Custo do reservatório adotado

\begin{tabular}{cccc}
\hline Capacidade $(\mathrm{L})$ & Quantidade & Valor unit $(\mathrm{R} \$)$ & Total $(\mathrm{R} \$)$ \\
\hline 5000 & 1 & $6.005,00$ & $6.005,00$ \\
10000 & 3 & $12.115,00$ & $36.345,00$ \\
& & & $42.350,00$ \\
\hline
\end{tabular}

Com os custos do reservatório pôde-se estimar o retorno financeiro pelo payback simples. Como as instalações prediais de água pluvial já são definidas em projeto, os custos destas não foram inseridas, nem os da mão de obra. Apenas o correspondente ao reservatório.

Como as taxas de água são $\mathrm{R} \$ 13,89 / \mathrm{m}^{3}$ e as de esgoto $\mathrm{R} \$$ $6,90 / \mathrm{m}^{3}$ para consumos superiores a $90.000 \mathrm{~L}$. mês ${ }^{-1}$, conforme tarifas da Companhia Pernambucana de Saneamento (COMPESA), totaliza-se $\mathrm{R} \$ 20,79 / \mathrm{m}^{3}$.

Dado o reservatório de $33 \mathrm{~m}^{3}$ dimensionado pelo método computacional Netuno, obteve-se um potencial de economia de água potável de 3,48\%, havendo um consumo de 3762,06 L.dia ${ }^{-1}$ de água da chuva para regas do jardim.

Sendo assim, o volume aproveitado anualmente de água de chuva é de $1373,1519 \mathrm{~m}^{3}$. Desta forma, o custo da água economizada por ano é de $\mathrm{R} \$ 28.547,83$. Como o custo dos reservatórios, sem a instalação e os acessórios, foi de $\mathrm{R} \$$ 42.350,00, o tempo de retorno do investimento é de 1,48 anos, aproximadamente 18 meses. 


\section{Discussões}

Os sistemas e técnicas para captação e aproveitamento da água da chuva têm sido implementados em todo o mundo de modo a atenuar os efeitos da variabilidade interanual nas precipitações e manter o bem-estar social [9]. Países como Austrália, Estados Unidos, China e Cingapura têm desenvolvido pesquisas referentes ao tema. Em 1992, foi iniciado o sistema de uso de água pluvial no Aeroporto de Chagi, em Cingapura. A água da chuva captada nas pistas de decolagem e aterrissagem é coletada, armazenada e utilizada para descarga dos banheiros [10].

$\mathrm{Na}$ China, resultados de recentes trabalhos mostram impactos positivos no uso de águas pluviais como fonte auxiliar de água não potável e a confiabilidade de SAAP's para aplicação em cidades e aldeias da região de Loess Plateau [11]. Ainda no continente asiático, estudos mais avançados na Malásia investigaram o desempenho de um sistema de filtração de carbono e areia ativada, combinada e auto preparada, para água da chuva e água do lago e fins de potabilidade [12]. Em geral, o sistema funcionou de forma satisfatória e oferece uma opção atrativa para as comunidades rurais por meio de uma fonte alternativa mediante tratamento da água da chuva colhida e da água do lago.

No Brasil, no estado de Minas Gerais, uma pesquisa objetivou o estudo da viabilidade técnica de implantação de um sistema de captação de águas pluviais em uma edificação pública de ensino superior recém-construída no município de Uberlândia [13]. A viabilidade econômica de implantação deste tipo de sistema está diretamente ligada aos custos envolvidos na construção do reservatório de acumulação. Nesse sentido, a pesquisa reforçou a importância em definir o volume otimizado que irá suprir uma determinada demanda por água da chuva, para determinada região com intensidade e frequência pluviométricas específicas, desencadeando o desenvolvimento de diversos métodos de dimensionamento.

Ainda neste contexto, uma pesquisa avaliou o potencial da economia de água potável pelo uso de água da chuva em 40 cidades da Amazônia. Os resultados da pesquisa indicam que, a depender da demanda de água potável verificada nas 40 cidades, o potencial médio de economia deste recurso foi de $76 \%$ [14]. Os autores salientam que, se existisse um programa para promover a economia de água potável por meio da utilização de água pluvial, haveria uma economia significativa de água potável, contribuindo, desta forma, para a preservação dos recursos hídricos do estado.

Dessa forma, os resultados apresentados na presente pesquisa mostram-se de acordo com tendências mundiais e nacionais de investigação do desempenho de SAAP's para fins não potáveis. Reforça-se, dentro da temática específica do artigo, a necessidade de contínuo desenvolvimento de trabalhos sobre gestão da água da chuva em conformidade com a arquitetura sustentável de edifícios, tendo em vista que efetivas adequações construtivas podem gerar economia de água potável em torno de $50 \%$ em determinada edificação [15].

\section{Conclusões}

A gestão dos recursos hídricos tem sido um dos maiores desafios lançados aos governantes, e à sociedade no geral, ao longo dos últimos anos, tendo em vista os graves problemas de escassez hídrica que afetam o mundo. Deste modo, torna-se cada vez mais necessária a busca pela conservação dos bens naturais, baseada na perspectiva sustentável e nas pequenas ações individuais, de modo a possibilitar uma melhor qualidade de vida para as gerações futuras.

Nessa perspectiva, o presente trabalho analisou a viabilidade técnica e econômica de implantar um sistema de captação de águas pluviais para fins não potáveis, no uso da rega de jardins, em um empreendimento residencial em construção na cidade do Recife, Pernambuco.

Por meio dos dados coletados e estimados, procurou-se definir o volume ideal do reservatório de acumulação de água da chuva, de tal forma a suprir por completo, ou quase toda a demanda, gerando o maior potencial de economia de água potável possível.

Utilizou-se o programa computacional Netuno, bastante adotado em pesquisas por proporcionar o potencial de economia de água potável e a porcentagem de completo atendimento da demanda. Foi admitida a hipótese da coleta de água em todas as cobertas do empreendimento, visto que as instalações prediais de captação e destinação da água pluvial já são previstas no projeto da construção, e por ter uma média de atendimento completo de $81,06 \%$.

Por meio da análise de viabilidade econômica realizada para implantação dos reservatórios de captação de água pluvial, pôde-se verificar que o custo destes corresponde a 2,63\% do orçamento para todas as instalações hidrossanitárias da obra. Sendo o custo total das instalações prediais de água pluvial previstas em projeto de $\mathrm{R} \$ 88.484,62$, ao incluir as cisternas o valor seria de $\mathrm{R} \$ 130.834,62$, um aumento de $47,86 \%$, retornáveis em 18 meses calculados pelo payback simples.

Portanto, pôde-se concluir que a implantação de um sistema de aproveitamento de água pluvial em um empreendimento deste porte se mostrou tecnicamente e economicamente viável para a obra em questão. O SAAP dimensionado pode atender a quase toda a demanda requisitada para rega de jardins, todos os dias do mês, trazendo benefícios ambientais e financeiros futuros para os moradores deste empreendimento, além de valorização do imóvel e da construtora como um todo. 


\section{Agradecimentos}

As autoras agradecem à Universidade de Pernambuco (UPE), em especial ao Grupo de Recursos Hídricos da Escola Politécnica de Pernambuco (AQUAPOLI) e ao Programa de PósGraduação em Engenharia civil (PEC-POLI) pelo suporte no desenvolvimento deste trabalho.

\section{IMPLEMENTATION ANALYSIS OF A RAINWATER HARVESTING SYSTEM IN A RESIDENTIAL BUILDING IN RECIFE-PE}

\begin{abstract}
Rainwater use systems for non-potable purposes in buildings represent one of the measures to reduce the demand for drinking water and minimize the problems related to the availability of water resources. In this perspective, this study aims to evaluate the technical and financial viability of implementing this system in a residential building located in the metropolitan region of Recife through a simulation, using rainwater for nonpotable purposes in garden watering. To this end, a study of rainfall data in the region and its periodicity were developed, evaluating the months of higher and lower rainfall. The storage tank was sized through the computational method Neptune and in different scenarios of catchment area, in order to determine the ideal situation to supply the demand to garden watering monthly. In addition, an analysis was made taking into account the typology of the building and estimated data. The economic analysis of the rainwater system construction showed that its implementation in a residential building with characteristics similar to that used in the study is technically and economically viable.
\end{abstract}

Keywords: Systems for non-potable purposes. Storage tank. Neptune.

\section{Referências}

[1] MARINOSKI, A.K. Aproveitamento de Água Pluvial para Fins Não Potáveis em Instituição de Ensino: Estudo de Caso em Florianópolis - SC. Trabalho de Conclusão de Curso. Curso de Graduação em Engenharia Civil, Universidade Federal de Santa Catarina - UFSC, Florianópolis, 2007.

[2] PICCOLI, A. S.; KLIGERMAN, D. C.; COHEN, S. C.; ASSUMPÇÃO, R. F. A educação ambiental como estratégia de mobilização social para o enfrentamento da escassez de água. Ciência \& Saúde Coletiva, vol. 21, n. 3, p. 797-808, 2016.

[3] MACIEL, D.H.B. Medidas para Conservação de Água em Habitações de Interessa Social na Cidade do Recife, PE. Dissertação (Mestrado) - Mestrado em Engenharia Civil,
Programa de Pós-graduação em Engenharia Civil, Universidade de Pernambuco, Recife, 2014.

[4] TOMAZ, P. Aproveitamento de Água de Chuva - Para Áreas Urbanas e Fins não Potáveis. São Paulo: Navegar Editora, 2003.

[5] ABNT. Associação Brasileira de Normas Técnicas. NBR 15.527 - Água de Chuva - Aproveitamento de coberturas em áreas urbanas para fins não potáveis - Requisitos, 2007.

[6] TOMAZ, P. Aproveitamento de Água da Chuva. Capítulo 22. São Paulo: Edição própria, 2010.

[7] CREDER, H. Instalações hidráulicas e sanitárias. Rio de Janeiro: editora LTC, 2006.

[8] ABNT. Associação Brasileira de Normas Técnicas. NBR 10.844 - Instalações Prediais de Águas Pluviais, 1989.

[09] BITTERMAN, P.; TATE, E.; METER, K. J. V.; BASU, N. B. Water security and rainwater harvesting: A conceptual framework and candidate indicators. Applied Geography, vol. 76, p.75-84, 2016.

[10] GROUP RAINDROPS. Aproveitamento da Água de Chuva. Editora Organic Trading, $1^{\mathrm{a}}$ Edição, Curitiba, 2002.

[11] GUOZHEN, Z.; YUANCHAO, Y.; XIADONG, L.; WEINA, Z. Research and Application of harvested rainwater in the villages and towns of China Loess Plateau region. Energy Procedia, [s.1.], vol. 5, p.307-313, 2011.

[12] SHAHEED, R.; MOHTAR, W. H. M. W.; EL-SHAFIE, A. Ensuring water security by utilizing roof-harvested rainwater and lake water treated with a low-cost integrated adsorption-filtration system. Water Science And Engineering, v. 10, n. 2, p.115-124, abr. 2017.

[13] SALLA, M.R.; LOPES, G.B.; PEREIRA, C.E.; NETO, J.C.N; PINHEIRO, A.M. Viabilidade técnica de implantação de sistema de aproveitamento de água pluvial para fins não potáveis em universidade. Ambiente Construído, Porto Alegre, vol. 13, n. 2, p.167-181, jun. 2013.

[14] LIMA, J.A.; DAMBROS, M.V.; ANTONIO, M.A.; JANZEN, J.G.; MARCHETTO, M. Potencial da economia de água potável pelo uso de água pluvial: análise de 40 cidades da Amazônia. Eng. Sanit. Ambiental, vol.16, n.3, p. 291-298, 2011.

[15] ZELEňÁKOVÁ, M.; MARKOVIC, G.; KAPOSZTASOVA, D.; VRANAYOVA, Z. Rainwater Management in Compliance with Sustainable Design of Buildings. Procedia Engineering, [s.1.], vol. 89, p.1515-1521, 2014. 